\title{
Effect of inclusion or non-inclusion of short lactations and cow and/or dam genetic group on genetic evaluation of Girolando dairy cattle
}

\author{
A.W. Canaza-Cayo', M.V.G.B. Silva ${ }^{2}$, J.A. Cobuci ${ }^{3}$, M.F. Martins ${ }^{2}$ and P.S. Lopes ${ }^{4}$ \\ ${ }^{1}$ Facultad de Ciencias Agrarias, Universidad Nacional del Altiplano, Puno, Peru \\ ${ }^{2}$ Embrapa Gado de Leite, Juiz de Fora, MG, Brasil \\ ${ }^{3}$ Departamento de Zootecnia, Universidade Federal do Rio Grande do Sul, \\ Porto Alegre, RS, Brasil \\ ${ }^{4}$ Departamento de Zootecnia, Universidade Federal de Viçosa, Viçosa, MG, Brasil \\ Corresponding author: P.S. Lopes \\ E-mail: plopes@ufv.br \\ Genet. Mol. Res. 15 (2): gmr.15027768 \\ Received September 1, 2015 \\ Accepted November 17, 2015 \\ Published April 4, 2016 \\ DOI http://dx.doi.org/10.4238/gmr.15027768
}

ABSTRACT. The objective of this study was to evaluate the effects of inclusion or non-inclusion of short lactations and cow (CGG) and/or dam (DGG) genetic group on the genetic evaluation of 305-day milk yield (MY305), age at first calving (AFC), and first calving interval (FCl) of Girolando cows. Covariance components were estimated by the restricted maximum likelihood method in an animal model of single trait analyses. The heritability estimates for MY305, AFC, and FCl ranged from 0.23 to $0.29,0.40$ to 0.44 , and 0.13 to 0.14 , respectively, when short lactations were not included, and from 0.23 to $0.28,0.39$ to 0.43 , and 0.13 to 0.14 , respectively, when short lactations were included. The inclusion of short lactations caused little variation in the variance components and heritability estimates of traits, but their non-inclusion resulted in the re-ranking of animals. Models with CGG or DGG fixed effects had higher heritability 
estimates for all traits compared with models that consider these two effects simultaneously. We recommend using the model with fixed effects of CGG and inclusion of short lactations for the genetic evaluation of Girolando cattle.

Key words: Genetic group; Girolando; Heritability; Short lactation; Variance components

\section{INTRODUCTION}

The dairy sector plays a significant part in Brazilian agribusiness, with approximately $80 \%$ of milk being produced by Girolando cows. This breed was developed in the 1940s by crossing Gyr and Holstein breeds. The animals of this breed are capable of maintaining good production standards under different management systems and climates (Silva et al., 2011).

One of the main problems facing milk production in tropical systems is the length of lactation (Madalena, 1988). Although short lactations are commonly associated with cows of the Zebu breed, they have been reported in different Holstein-Gyr genetic groups. This difference has been associated with genetic and non-genetic effects (Madalena, 1988). Vercesi-Filho et al. (2007) observed a high genetic correlation between milk production and lactation length (0.93) in crossbred dairy cattle in Brazil, indicating that short-lactation periods should not be discarded from genetic evaluations.

However, in Brazil, data on short lactations are not often included when editing milk production records or when using adjustment factors (Facó et al., 2009; Baldi et al., 2011). The definition of short lactation varies and is arbitrary, but intervals of 120-210 days have been used (Vaccaro et al., 1999). However, this tends to overestimate the genetic parameters associated with milk production and the lactation length, which reduces the accuracy of selection processes (Vaccaro et al., 1999).

The non-inclusion of short lactation and adjusting for lactation length reduce the genetic variance associated with milk production (Madalena, 1988; Mello et al., 1994). On the other hand, Facó et al. (2009) observed that the non-inclusion of short lactations did not reduce the genetic variance and also contributed to a significant reduction in the residual variance. In addition, Baldi et al. (2011) observed that adjusting for production records and the inclusion of short lactations caused changes in the ranking of bulls for selection purposes.

Studies including the effect of cow and/or dam genetic group on dairy cattle genetic valuation are scarce in the literature. Working with Girolando cattle, Facó et al. (2007) reported a heritability estimate for milk yield of 0.31 using a single-trait model that included the fixed effects of cow and dam genetic groups. However, in a study by Facó et al. (2009), these estimates ranged from 0.24 to 0.31 in an animal model that only included the cow genetic group.

Therefore, the objectives of the present study were a) to evaluate the effect of inclusion or non-inclusion of short lactations on the variance components and heritability estimates for milk yield, age at first calving, and the first calving interval and b) to evaluate the effect of the inclusion of cow and/or dam genetic effects in the model on the components of variance, heritabilities, and classification of the animals for these traits in Girolando cows.

\section{MATERIAL AND METHODS}

The initial database used in this study included 86,863 records from the National Dairy Cattle Archive (Arquivo Zootécnico Nacional de Gado de Leite), which was provided by the 
Genetic Improvement Program for Girolando Cattle (Programa de Melhoramento Genético da Raça Girolando, PMGG) under the management of Embrapa Dairy Cattle in partnership with the Brazilian Girolando Breeders' Association (Associação Brasileira dos Criadores de Girolando). Traits considered were 305-day milk yield at first lactation (MY305), age at first calving (AFC), and the first calving interval $(\mathrm{FCl})$.

The productive or reproductive records were subjected to several restrictions and eliminations for each trait. Records of lactations shorter than 100 days and longer than 730 days were discarded to generate "Records with non-inclusion of short lactations (RNSL)". Additionally, $305-$ day milk yields higher than $20,000 \mathrm{~kg}$ and cows whose calving year was before 2000 and after 2011 were also discarded. After the eliminations, the data file RNSL consisted of 10,900 records of MY305 and AFC, and 7239 records of $\mathrm{FCl}$ measured in 288 herds.

Records from cows belonging to genetic groups $1 / 4 \mathrm{H}: 3 / 4 \mathrm{G}, 3 / 8 \mathrm{H}: 5 / 8 \mathrm{G}, 1 / 2 \mathrm{H}: 1 / 2 \mathrm{G}$, $5 / 8 \mathrm{H}: 3 / 8 \mathrm{G}, 3 / 4 \mathrm{H}: 1 / 4 \mathrm{G}, 7 / 8 \mathrm{H}: 1 / 8 \mathrm{G}$, with pure dams of the Holstein $(\mathrm{H})$ or $\mathrm{Gyr}(\mathrm{G})$ breeds or pertaining to these genetic groups, respectively, represented by $1 / 4,3 / 8,1 / 2,5 / 8,3 / 4,7 / 8, \mathrm{H}$, and $\mathrm{G}$, were used. Of the 830 records from short lactations, only those that presented a normal cause of drying-off were considered. With this restriction, the final number of short lactations was 277 ( $2.5 \%$ of total). Thus, the data file including short lactations consisted of 11,177 records, and was thus named "Records with inclusion of short lactations (RISL)".

In both files (RNSL and RISL), contemporary groups (herd-calving year for MY305 and $\mathrm{FCl}$ and herd-birth year for AFC) that contained at least three records of production and at least three daughters from two bulls per group were used. The pedigree file used for computing the numerator relationship matrix (NRM) included a total of 26,969 animals.

Table 1 shows the distribution of observations, according to the genetic groups of cows and dams. The distribution of animals according to the cow genetic group (CGG) was greater in fractions $1 / 2,5 / 8$, and $3 / 4$ in the data files with inclusion and non-inclusion of short lactations. In the dam genetic group (DGG), fractions $1 / 4,1 / 2$, and $3 / 4$ presented a higher number of animals.

Table 1. Distribution of animals according to the cow genetic group (CGG) and dam genetic group (DGG) with inclusion or non-inclusion of short lactations and only short lactations.

\begin{tabular}{|c|c|c|c|c|c|c|}
\hline \multirow{2}{*}{ Genetic group } & \multicolumn{2}{|c|}{ RNSL } & \multicolumn{2}{|c|}{ RISL } & \multicolumn{2}{|c|}{ Only short lactations } \\
\hline & CGG & DGG & CGG & DGG & CGG & DGG \\
\hline $1 / 4$ & 275 & 1430 & 291 & 1455 & 16 & 25 \\
\hline $3 / 8$ & 425 & 29 & 438 & 30 & 13 & 1 \\
\hline $1 / 2$ & 2706 & 2912 & 2794 & 3002 & 88 & 90 \\
\hline $5 / 8$ & 3417 & 877 & 3491 & 894 & 74 & 17 \\
\hline $3 / 4$ & 3251 & 2384 & 3328 & 2426 & 77 & 42 \\
\hline $7 / 8$ & 826 & 476 & 835 & 490 & 9 & 14 \\
\hline $\mathrm{H}$ & - & 1091 & - & 1116 & - & 25 \\
\hline G & - & 1701 & - & 1764 & - & 63 \\
\hline Total & 10,900 & 10,900 & 11,177 & 11,177 & 277 & 277 \\
\hline
\end{tabular}

RNSL = records with non-inclusion of short lactations; RISL = records with inclusion of short lactations.

The means and standard deviations for the traits studied are presented in Table 2. Cows from genetic group 7/8 presented greater MY305 and those from genetic group 1/4 showed higher $\mathrm{AFC}$ and $\mathrm{FCl}$. 
Table 2. Means and standard deviations of the traits milk yield at 305 days of lactation (MY305), age at first calving (AFC), and first calving interval ( $F C l)$, according to the cow genetic group, with inclusion or non-inclusion of short lactations.

\begin{tabular}{l|c|c|c|c|c|c}
\hline \multirow{2}{*}{ Genetic group } & \multicolumn{3}{|c|}{ RNSL } & \multicolumn{3}{c}{ RISL } \\
\cline { 2 - 7 } & MY305 $(\mathrm{kg})$ & AFC (days) & FCl (days) & MY305 (kg) & AFC (days) & FCl (days) \\
\hline $1 / 4$ & $3059 \pm 1724$ & $1183 \pm 167$ & $440 \pm 76$ & $2930 \pm 1763$ & $1180 \pm 165$ & $440 \pm 76$ \\
\hline $3 / 8$ & $3502 \pm 1935$ & $1165 \pm 155$ & $422 \pm 70$ & $3418 \pm 1967$ & $1165 \pm 154$ & $423 \pm 71$ \\
\hline $1 / 2$ & $4000 \pm 1788$ & $1047 \pm 180$ & $413 \pm 70$ & $3900 \pm 1845$ & $1048 \pm 180$ & $413 \pm 70$ \\
\hline $5 / 8$ & $3508 \pm 1699$ & $1096 \pm 184$ & $425 \pm 73$ & $3449 \pm 1729$ & $1097 \pm 184$ & $425 \pm 73$ \\
\hline $3 / 4$ & $4322 \pm 1777$ & $1055 \pm 180$ & $416 \pm 70$ & $4246 \pm 1826$ & $1057 \pm 180$ & $416 \pm 70$ \\
\hline $7 / 8$ & $4507 \pm 1943$ & $1077 \pm 182$ & $423 \pm 73$ & $4469 \pm 1967$ & $1077 \pm 182$ & $423 \pm 73$ \\
\hline Overall mean & $3937 \pm 1817$ & $1075 \pm 183$ & $419 \pm 72$ & $3861 \pm 1858$ & $1076 \pm 183$ & $419 \pm 71$ \\
\hline
\end{tabular}

RNSL = records with non-inclusion of short lactations; RISL = records with inclusion of short lactations.

The effect of inclusion or non-inclusion of short lactations on the variance components, heritabilities, and ranking of animals for traits was evaluated by comparing the estimates obtained from the RNSL and RISL databases. The importance of the inclusion of CGG or DGG effects in the animal model on the estimates of variance components and heritability was evaluated by comparing the models that included or did not include fixed effects of CGG and DGG, separately or simultaneously.

The model used to estimate the variance components and to predict the breeding values of the animals for traits MY305 and FCl (model a) was:

$$
\mathrm{y}_{\mathrm{ijk} k}=\mathrm{CG}_{\mathrm{i}}+\mathrm{CS}_{\mathrm{j}}+\mathrm{CGG}_{\mathrm{k}}+\mathrm{b}_{1}\left(\mathrm{I}_{\mathrm{ijkl}}-\overline{\mathrm{I}}\right)+\mathrm{b}_{2}\left(\mathrm{I}_{\mathrm{ijk} \mathrm{kl}}-\overline{\mathrm{I}}\right)^{2}+\mathrm{a}_{\mathrm{ijkl}}+\mathrm{e}_{\mathrm{ijk} \mathrm{l}} \quad \text { (Equation 1) }
$$

where $y_{i j k l}=\mathrm{MY} 305$ or $\mathrm{FCl}$ observed in animal $l$, from genetic group $k$, at time $j$, from the contemporary group $i ; \mathrm{CG}_{i}=$ fixed effect of the $i$-th contemporary group (herd-calving year), where $i=1,2, \ldots, 951$; $\mathrm{CS}_{j}=$ fixed effect of the $j$-th calving season, where $j=1$ (Oct to Mar) and 2 (Apr to Sep); $\mathrm{CGG}_{k}=$ fixed effect of the $k$-th cow genetic group, where $k=1,2, \ldots, 6 ; b_{1}$ and $b_{2}=$ linear and quadratic regression coefficients of trait $y_{i j k l}$ according to the age at calving, included in the model as covariate; $i_{i j k l}$ age at calving, in months; $\bar{l}=$ average age at calving, in months; $a_{i j k l}$ additive genetic random effect of animal $I$, from genetic group $k$, at calving season $j$, from contemporary group $i ; e_{i j k l}$ random error associated with each observation, assumed to be normal and independent. Models $b$ and $c$ are similar to model $a$ in (1), replacing the effect of CGG by DGG in the first instance (model $b$ ), and including the DGG effect in the second case (model $c$ ).

For the trait AFC, the following model was used (model a):

$$
\mathrm{y}_{\mathrm{ijkl}}=\mathrm{CG}_{\mathrm{i}}+\mathrm{BS}_{\mathrm{j}}+\mathrm{CGG}_{\mathrm{k}}+\mathrm{a}_{\mathrm{ijkl}}+\mathrm{e}_{\mathrm{ijkl}}
$$

where $y_{i j k l}=$ AFC of animal $l$, from genetic group $k$, at birth season $j$, from the contemporary group $i ; \mathrm{CG}_{i}=$ fixed effect of the $i$-th contemporary group (herd-year of birth), where $i=1,2, \ldots, 1183 ; \mathrm{BS}_{j}$ $=$ fixed effect of the $j$-th birth season, where $j=1$ (Oct to Mar) and 2 (Apr to Sep); and the CGG $a_{i j k l}$ and $e_{i j k l}$ effects were previously defined in Equation 1. Models $b$ and $c$ are similar to model $a$ in Equation 2, but replacing the effect of CGG by DGG in the first instance (model $b$ ) and including the DGG effect in the latter (model $c$ ). 
Spearman correlations compared the classification of animals based on the additive breeding values predicted for the traits MY305, AFC, and $\mathrm{FCl}$. The percentages of bulls and cows in common were also calculated when different proportions of animals were selected based on the breeding values predicted using different models ( $a, b$, and $c)$, according to the inclusion or noninclusion of short lactations.

Estimates of variance components were obtained by the restricted maximum likelihood (REML) method, using the Wombat software (Meyer, 2007).

\section{RESULTS}

The variance components and the heritability estimates of the traits according to the inclusion or non-inclusion of short lactations are presented in Table 3. Overall, the estimates of genetic additive, residual, and phenotypic variances for MY305 were lower when short lactations were excluded, regardless of the genetic group. When short lactations were excluded, the genetic additive and residual variances for MY305 were reduced by 7 and $9 \%$, respectively, in model a (CGG); by 2 and $9 \%$ in model $b$ (DGG); and by 4 and $8 \%$ in model $c$ (CGG and DGG), respectively. Decreases in the residual variances were relatively low, making the heritability estimates similar with the inclusion or non-inclusion of short lactations (i.e., RISL and RNSL). These results indicate that the non-inclusion of short lactations imply low reduction in the additive genetic and residual variances for MY305 in the three models.

For AFC, the estimates of genetic additive variance were lower in RISL. Estimates of residual variance were higher in RISL. For $\mathrm{FCl}$, the estimates of genetic additive variance were higher in RISL. Changes in the estimates of genetic additive variance were similar in models $a, b$, and $c$ for $\mathrm{AFC}$ (decrease of $\sim 3 \%$ in RISL) and $\mathrm{FCl}$ (increase of $\sim 2 \%$ in RISL). Due to small changes in the estimates of variance components, the heritability estimates were very close in RNSL and RISL in models $a, b$, and $c$.

Table 3. Estimates of variance components and heritability for the traits milk yield at 305 days of lactation (MY305), age at first calving (AFC), and first calving interval ( $F C l)$, according to the inclusion or non-inclusion of short lactations.

\begin{tabular}{l|c|c|c|c|c|c|c}
\hline \multirow{2}{*}{ Component } & \multirow{2}{*}{ Model } & \multicolumn{3}{|c|}{ RNSL } & \multicolumn{2}{c}{ RISL } \\
\cline { 3 - 8 } & & MY305 & AFC & FCI & MY305 & AFC & FCI \\
\hline Additive & $a$ & 451,310 & 9877.7 & 559.91 & 487,275 & 9590.58 & 567.27 \\
\hline & $b$ & 517,620 & 9291.5 & 576.69 & 530,701 & 9099.38 & 587.20 \\
\hline Residual & $c$ & 396,410 & 8975.9 & 545.23 & 414,949 & 8742.62 & 554.15 \\
\hline & $a$ & $1,248,000$ & 12,788 & 3664.3 & $1,366,630$ & $12,945.6$ & 3652.7 \\
\hline & $b$ & $1,233,500$ & 13,237 & 3658.3 & $1,359,710$ & $13,325.5$ & 3644.7 \\
\hline Phenotypic & $c$ & $1,301,300$ & 13,383 & 3679.6 & $1,416,620$ & $13,486.4$ & 3667.3 \\
\hline & $a$ & $1,699,310$ & $22,665.7$ & 4224.2 & $1,853,910$ & $22,536.2$ & 4220.0 \\
\hline & $b$ & $1,751,120$ & $22,528.5$ & 4235.0 & $1,890,410$ & $22,424.9$ & 4231.9 \\
\hline Heritability & $c$ & $1,697,710$ & $22,358.9$ & 4224.8 & $1,831,570$ & $22,229.0$ & 4221.5 \\
\hline & $a$ & $0.27 \pm 0.03$ & $0.44 \pm 0.03$ & $0.13 \pm 0.04$ & $0.26 \pm 0.03$ & $0.43 \pm 0.03$ & $0.13 \pm 0.04$ \\
\hline & $b$ & $0.29 \pm 0.03$ & $0.41 \pm 0.03$ & $0.14 \pm 0.04$ & $0.28 \pm 0.03$ & $0.41 \pm 0.03$ & $0.14 \pm 0.04$ \\
\hline & $c$ & $0.23 \pm 0.03$ & $0.40 \pm 0.03$ & $0.13 \pm 0.04$ & $0.23 \pm 0.03$ & $0.39 \pm 0.03$ & $0.13 \pm 0.04$ \\
\hline
\end{tabular}

$a$ - model that adjusts the effect of cow genetic group (CGG); $b$ - model that adjusts the effect of dam genetic group (DGG); $c$ - model that adjusts the effect of CGG and DGG. RNSL = records with non-inclusion of short lactations; RISL $=$ records with inclusion of short lactations. 
In general, the Spearman correlation coefficients between the predicted breeding values of bulls and cows for MY305 were higher in RISL (Table 4). For AFC, the correlations were slightly higher for RISL in bulls, whereas for $\mathrm{FCl}$, there was no difference in the correlations for RNSL and RISL in bulls and cows.

Table 4. Spearman correlation coefficients between the breeding values of bulls and cows for milk yield at 305 days of lactation (MY305), age at first calving ( $A F C$ ), and first calving interval (FCI) predicted by the models with inclusion or non-inclusion of short lactations.

\begin{tabular}{l|c|c|c|c|c}
\hline \multirow{2}{*}{ Trait } & \multirow{2}{*}{ Model } & \multicolumn{2}{|c|}{ RNSL } & \multicolumn{2}{c}{ RISL } \\
\cline { 3 - 6 } & & Bulls & Cows & Bulls & Cows \\
\hline MY305 & $a$ vs $b$ & 0.83 & 0.90 & 0.93 & 0.94 \\
\hline & $a$ vs $c$ & 0.96 & 0.97 & 0.96 & 0.96 \\
\hline & $b$ vs $c$ & 0.80 & 0.87 & 0.90 & 0.91 \\
\hline AFC & $a$ vs $b$ & 0.97 & 0.98 & 0.98 & 0.98 \\
\hline & $a$ vs $c$ & 0.96 & 0.98 & 0.96 & 0.98 \\
\hline & $b$ vs $c$ & 0.94 & 0.97 & 0.99 & 0.96 \\
\hline FCl & $a v s b$ & 0.99 & 0.99 & 1.00 & 1.00 \\
\hline & $a$ vs $c$ & 1.00 & 1.00 & 0.99 & 0.99 \\
\hline
\end{tabular}

$a$ - model that adjusts the effect of cow genetic group (CGG); $b$ - model that adjusts the effect of dam genetic group (DGG); $c$ - model that adjusts the effect of CGG and DGG. RNSL = records with non-inclusion of short lactations; RISL $=$ records with inclusion of short lactations. All correlation coefficients are statistically different from zero $(P<0.0001)$.

Table 5 presents the percentages of bulls and cows in common when different proportions of animals were selected, according to the inclusion or non-inclusion of short lactations in the analysis. The percentages of bulls and cows in common in models $a$ and $b$ were higher when short lactations were included (RISL) in all traits evaluated in the different proportions of animals selected. However, the percentage of bulls and cows in common was lower in model a vs model c when short lactations were included (RISL) for MY305.

Table 5. Percentage of bulls and cows in common when different proportions of animals were selected based on the breeding value predicted for the traits evaluated, according to the inclusion or non-inclusion of short lactations.

\begin{tabular}{|c|c|c|c|c|c|c|c|c|c|c|c|c|}
\hline \multirow{3}{*}{$p(\%)^{1}$} & \multicolumn{6}{|c|}{$\mathrm{RNSL}^{2}$} & \multicolumn{6}{|c|}{$\mathrm{RISL}^{2}$} \\
\hline & \multicolumn{2}{|c|}{ MY305 } & \multicolumn{2}{|c|}{ AFC } & \multicolumn{2}{|c|}{$\mathrm{FCl}$} & \multicolumn{2}{|c|}{ MY305 } & \multicolumn{2}{|c|}{$\mathrm{AFC}$} & \multicolumn{2}{|c|}{$\mathrm{FCl}$} \\
\hline & $\mathrm{B}(\%)$ & C (\%) & $\mathrm{B}(\%)$ & C (\%) & B (\%) & C (\%) & $\mathrm{B}(\%)$ & C (\%) & $\mathrm{B}(\%)$ & C (\%) & $\mathrm{B}(\%)$ & C (\%) \\
\hline & \multicolumn{10}{|c|}{ Model $a$ vs Model $b$} & & \\
\hline 1 & 75 & 81 & 75 & 81 & 83 & 91 & 90 & 87 & 90 & 80 & 100 & 91 \\
\hline 5 & 77 & 76 & 85 & 86 & 87 & 93 & 88 & 83 & 82 & 85 & 87 & 94 \\
\hline 10 & 80 & 76 & 84 & 88 & 92 & 95 & 83 & 82 & 84 & 82 & 90 & 94 \\
\hline 20 & 83 & 83 & 89 & 91 & 97 & 95 & 86 & 86 & 90 & 89 & 94 & 94 \\
\hline 40 & 84 & 86 & 92 & 93 & 98 & 96 & 90 & 92 & 94 & 96 & 95 & 97 \\
\hline \multirow[t]{2}{*}{60} & 88 & 90 & 96 & 96 & 98 & 98 & 93 & 92 & 95 & 95 & 98 & 98 \\
\hline & & & \multicolumn{8}{|c|}{ Model a vs Model $c$} & & \\
\hline 1 & 83 & 90 & 71 & 83 & 100 & 96 & 80 & 79 & 100 & 80 & 100 & 98 \\
\hline 5 & 82 & 87 & 85 & 87 & 97 & 97 & 82 & 77 & 86 & 85 & 97 & 98 \\
\hline 10 & 84 & 88 & 83 & 89 & 95 & 99 & 80 & 78 & 85 & 89 & 97 & 99 \\
\hline 20 & 86 & 89 & 86 & 91 & 98 & 98 & 80 & 82 & 91 & 91 & 98 & 96 \\
\hline 40 & 92 & 92 & 91 & 93 & 98 & 99 & 88 & 89 & 94 & 97 & 98 & 99 \\
\hline 60 & 95 & 94 & 93 & 95 & 99 & 99 & 93 & 91 & 95 & 95 & 99 & 99 \\
\hline
\end{tabular}

$p(\%)=$ proportion of animals selected; $\mathrm{B}(\%)=$ percentage of bulls in common; $\mathrm{C}(\%)=$ percentage of cows in common. RNSL = records with non-inclusion of short lactations; RISL = records with inclusion of short lactations; MY305 = 305-day milk yield; $\mathrm{AFC}=$ age at first calving; $\mathrm{FCl}=$ first calving interval . 


\section{DISCUSSION}

In this study, the percentage of cows having lactation periods shorter than 100 days was only $2.5 \%$, which is lower than values reported in other studies. Vaccaro et al. (1999), working with Brahman, Holstein, and Braunvieh breeds, reported 3.8-4\% of short lactations, ranging from 1 to 100 days, whereas Mello et al. (1994) reported 4\% of short lactations, which were shorter than 120 days. However, Facó et al. (2009) reported $13.6 \%$ of lactations that were shorter than 120 days, with the greatest incidence $(21.1 \%)$ observed in animals belonging to the genetic group $1 / 4 \mathrm{H}: 3 / 4 \mathrm{G}$ and the lowest $(9.1 \%)$ in $7 / 8 \mathrm{H}: 3 / 8 \mathrm{G}$ animals.

The better performance obtained in milk production by genetic groups $7 / 8$ and $1 / 4$ is different from that reported in the literature. Facó et al. (2007) reported better performance for genetic groups $1 / 2$ and 3/4 in Girolando animals. Freitas et al. (1998) verified that 7/8 and 1/4 bulls were associated with greater milk yield when compared with $5 / 8$ bulls, and Mellado et al. (2011) reported greater milk yield for group $H$ (Holstein), followed by groups 1/4 and 1/2.

Differences in the components of residual and genetic additive variances were of lower magnitude than those obtained in other studies. Facó et al. (2009) observed that non-inclusion of short lactations of Girolando cows led to estimates of variance components that were lower than those obtained when all lactations were used. Those authors reported that the reductions were inferior for the additive (4\%) and permanent environmental variances $(10 \%)$ than for the residual variance $(24 \%)$, resulting in greater heritability for milk production with the non-inclusion of short lactations $\left(h^{2}=0.31\right)$ than with their inclusion $\left(h^{2}=0.27\right)$. However, Mello et al. (1994), studying the Gyr breed, reported reduction of genetic variance for MY305 with the non-inclusion of short lactations in comparison with their inclusion, which caused a decrease from 0.40 to 0.05 in the heritability estimates when lactations shorter than 120 days were excluded. The differences between the results of the present study and those previously reported may be due to differences in the size of the sample utilized [e.g., $N=398$ in the study of Mello et al. (1994)], standardization of milk production [e.g., milk production per lactation, in the study of Facó et al. (2009)], and definition of the effects in the model of analysis.

Overall, one can infer that there were no differences between the models with inclusion or non-inclusion of short lactations for the traits studied. However, the loss of additive variance was not significant when short lactations were excluded, thus approaching the results obtained by Facó et al. (2009) and Mackinnon et al. (1996), but disagreeing with the results of other studies (Madalena et al., 1992; Mello et al., 1994; Vercesi-Filho et al., 2007; Baldi et al., 2011).

Greater genetic additive and lower residual variances were observed in the model that included the dam genetic group (model $b$ ) for $\mathrm{MY} 305$ and $\mathrm{FCl}$. As a consequence, the heritability estimates of these two traits were slightly higher than those obtained in models $a$ and $c$. However, for $\mathrm{FCl}$, greater genetic variability and lower residual variance were obtained with the use of model a, so the heritability was slightly higher.

When model $c$ was utilized, all traits had lower heritability estimates. It was expected that the simultaneous inclusion of the effects of CGG and DGG would be more efficient to recover a significant proportion of the residual variance. A possible cause of this is the confounding result caused by multicollinearity when both effects were included in the model of analysis, even though the data were unbalanced for both. In a previous analysis of fixed effects, statistical significance of the interaction was observed between these effects, with significant and negative correlations between both effects. In addition, very low eigenvalues of the correlation matrix $(<1)$ were observed, which might have overestimated the residual variance (model $c$ ). 
The heritability estimates ranged from 0.23 to 0.28 for MY305 with inclusion, and from 0.23 to 0.29 with non-inclusion of short lactations, showing higher values in model $b$. Such estimates are similar to those reported in the literature. In a study with Brazilian crossbred dairy cattle, VercesiFilho et al. (2007) reported heritability estimates of 0.28 for MY305. Utilizing records of milk yield with non-inclusion of short lactations of the Girolando breed, Facó et al. (2007) found heritability estimates of 0.31 for milk production. Working with Murray buffalos, Tonhati et al. (2007) reported greater heritability estimates for milk production when they were adjusted for lactation length $(0.22$ to 0.27 ) than when they were not (0.16 to 0.18$)$.

The high heritability estimates for AFC found in the present study (0.39 to 0.44 ) are similar to those reported by Vercesi-Filho et al. (2007). Because of the high heritability and economic relevance of this trait, those authors recommended its inclusion in the criteria of selection for dairy cattle in the tropics. The heritability estimates for $\mathrm{FCl}(0.13$ to 0.14$)$ were not affected by the inclusion of short lactations; however, it showed slight superiority when model $b$ was used. The values obtained in the present study were superior to those obtained by Val et al. (2004), which were 0.10 for the Holstein breed; and Facó et al. (2008), which were 0.05 for the Girolando breed, but inferior to the value obtained by Bertipaglia et al. (2007) with Holstein cows (0.19).

Spearman correlations between the genetic values of bulls and cows were higher in the models with inclusion of short lactations. Except for the correlations between the genetic values of the bulls in models $a v s b$ and $b v s c$ and for cows in model $b v s c$ in the records with non-inclusion of short lactations, the other correlations were of high magnitude ( $\left.{ }^{3} 0.90\right)$. Facó et al. (2009) reported Spearman correlations of 0.89 between the genetic values predicted for milk production in records with inclusion and non-inclusion of short lactations, and the correlation value decreased as the intensity of selection increased. According to Crews Jr. and Franke (1998), correlations lower than 0.90 changed the rank of animals, which might affect the selection response and subsequent genetic progress. Therefore, although the best results were obtained with inclusion of short lactations, we can infer that there would not be significant changes in the ranking of animals with non-inclusion of short lactations in the database.

The higher Spearman correlation between the breeding values of bulls and cows observed between models $a$ and $c$ for MY305 may indicate the non-recommendation of inclusion of only the DGG effect in the models of genetic evaluation (model $b$ ). Spearman correlations between the breeding values of bulls and cows of the other traits, AFC and $\mathrm{FCl}$, were high ( $\left.{ }^{3} 0.94\right)$, which indicates that the inclusion of CGG, DGG, or CGG and DGG could be used to rank animals for selection purposes of these traits.

The percentage of bulls and cows in common (Table 5) corroborates the results obtained in the Spearman correlations. In a study with Murrah buffalos, Tonhati et al. (2007) found Spearman correlations between breeding values for milk production and percentage of bulls in common lower than those found in the present study. The authors concluded that in situations with high selection intensity, there will likely be modifications in the rank of bulls and/or in the bulls chosen for mating if records are adjusted or unadjusted for 305 days. Facó et al. (2007), working with Girolando dairy cattle and computing Spearman correlations between the breeding values predicted using single- and multiple-trait models, with inclusion of CGG and DGG effects, verified a trend towards reduction of the correlations when the selection intensities increased.

The models with CGG (model $a$ ) or DGG (model $b$ ) effects had greater impact on the estimates of variance components and heritability for all the traits than the model with the inclusion of the two effects (CGG and DGG, model c). However, the Spearman correlation between the breeding values of bulls and cows predicted by the models $a$ and $c$ was greater than by the models 
$a$ and $b$, which indicates the non-recommendation of inclusion of only DGG in the models of genetic evaluation. Therefore, we recommend use of the model including only the fixed effect of the CGG and the inclusion of records of milk production, age at first calving, and the first calving interval of animals with a short lactation length in the genetic evaluation of Girolando cattle.

\section{Conflicts of interest}

The authors declare no conflict of interest.

\section{ACKNOWLEDGMENTS}

The authors thank Associação Brasileira de Criadores de Girolando (ABCG) and Embrapa Gado de Leite for providing data.

\section{REFERENCES}

Baldi F, Laureano MMM, Gordo DGG, Bignardi AB, et al. (2011). Effect of lactation length adjustment procedures on genetic parameter estimates for buffalo milk yield. Genet. Mol. Biol. 34: 62-67. http://dx.doi.org/10.1590/S141547572011000100012

Bertipaglia ECA, Silva RG, Cardoso V and Maia ASC (2007). Estimativas de parâmetros genéticos e fenotípicos de características do pelame e de desempenho reprodutivo de vacas holandesas em clima tropical. Rev. Bras. Zootec. 36: 350-359. http://dx.doi.org/10.1590/S1516-35982007000200011

Crews DH, Jr. and Franke DE (1998). Heterogeneity of variances for carcass traits by percentage Brahman inheritance. J. Anim. Sci. 76: 1803-1809.

Facó O, Martins Filho R, Lôbo RNB, Oliveira SMP, et al. (2007). Heterogeneidade de (co)variância para a produção de leite nos grupos genéticos formadores da raça Girolando. Rev. Cienc. Agron. 38: 304-309.

Facó O, Lôbo RNB, Martins Filho R, Martins GA, et al. (2008). Efeitos genéticos aditivos e não-aditivos para características produtivas e reprodutivas em vacas mestiças Holandês x Gir. Rev. Bras. Zootec. 37: 48-53. http://dx.doi.org/10.1590/ $\underline{\text { S1516-35982008000100006 }}$

Facó O, Martins Filho R, Lôbo RNB, Azevêdo DMMR, et al. (2009). Efeito da redução da variação da duração de lactação na avaliação genética de bovinos leiteiros mestiços. Rev. Cienc. Agron. 40: 287-292.

Freitas AF, Wilcox CJ and Costa CN (1998). Breed group effects on milk production of Brazilian crossbred dairy cows. J. Dairy Sci. 81: 2306-2311. http://dx.doi.org/10.3168/jds.S0022-0302(98)75811-4

Mackinnon MJ, Thorpe W and Baker RL (1996). Sources of genetic variation for milk production in a crossbred herd in the tropics. Anim. Sci. 62: 5-16. http://dx.doi.org/10.1017/S1357729800014259

Madalena FE (1988). A note on the effect of variation of lactation length on the efficiency of tropical cattle selection for milk yield. Theor. Appl. Genet. 76: 830-834. http://dx.doi.org/10.1007/BF00273667

Madalena FE, Lemos AM and Teodoro RL (1992). Consequences of removing the variation in lactation length on the evaluation of dairy cattle breeds and crosses. Braz. J. Genet. 15: 585-593.

Mellado M, Coronel F, Estrada A and Rios FG (2011). Lactation performance of Holstein and Holstein x Gyr cattle under intensive condition in a subtropical environment. Trop. Subtrop. Agroecosyt. 14: 927-931.

Mello AA, Penna VM, Madalena FE and Pereira CS (1994). Efeito da eliminação de lactações curtas e do ajuste pela duração da lactação na herdabilidade da produção de leite em um rebanho Gir. Arch. Latinoam. Prod. Anim. 2: 117-123.

Meyer K (2007). WOMBAT: a tool for mixed model analyses in quantitative genetics by restricted maximum likelihood (REML). J. Zhejiang Univ. Sci. B 8: 815-821. http://dx.doi.org/10.1631/jzus.2007.B0815

Silva MVGB, Paiva LC, Cembranelli MAR, Martins MF, et al. (2011). Programa de Melhoramento Genético da raça Girolando - Teste de progênie: Sumário de Touros. Embrapa Gado de Leite, Juiz de Fora.

Tonhati H, Baldi FS, Laureano MMM and Albuquerque LG (2007). Genetic parameters for milk yield of Bubalus bubalis using unadjusted and adjusted milk production for days in milk. Ital. J. Anim. Sci. 6: 310-313.

Vaccaro L, Velázquez E, Pérez A and Mejías H (1999). Lactation length in Venezuelan dual-purpose cows. J. Anim. Breed. Genet. 116: 509-517. http://dx.doi.org/10.1046/j.1439-0388.1999.00206.x

Val JE, Freitas MAR, Oliveira HN, Cardoso VL, et al. (2004). Indicadores de desempenho em rebanho da raça Holandesa: curvas de crescimento e altura, características reprodutivas, produtivas e parâmetros genéticos. Arq. Bras. Med. Vet. Zootec. 56: 86-93. http://dx.doi.org/10.1590/S0102-09352004000100014

Vercesi-Filho AE, Madalena FE, Albuquerque LG, Freitas AF, et al. (2007). Parâmetros genéticos entre características de leite, de peso e a idade ao primeiro parto em gado mestiço leiteiro (Bos taurus x Bos indicus). Arq. Bras. Med. Vet. Zootec. 59: 983-990. http://dx.doi.org/10.1590/S0102-09352007000400026 